\title{
Presence of the full-length KIR2DS4 gene reduces the chance of rheumatoid arthritis patients to respond to methotrexate treatment
}

\author{
Edyta Majorczyk ${ }^{1,2^{*}}$, Andrzej Pawlik ${ }^{3}$, Daria Gendosz ${ }^{1}$ and Piotr Kuśnierczyk ${ }^{1 *}$
}

\begin{abstract}
Background: KIR genes coding for natural killer cell immunoglobulin-like receptors, KIR, influence the effector and regulatory function of NK cells as well as some subpopulations of T lymphocytes (e.g. CD4+CD28-KIR+) depending on presence of ligands (particularly HLA-C molecules). KIR-KIR ligand interaction may lead to the development of autoimmune disorders, including rheumatoid arthritis (RA). However, their role in the response of RA patients to methotrexate therapy is not known.
\end{abstract}

Methods: KIR genes and KIR-ligand (HLA-C C1/C2 allomorphs) genotyping was performed using the PCR-SSP method in 312 RA patients (179 classified as good responders and 133 as poor responders using DAS28 criteria). Thus, we evaluated the association of KIR genes and HLA-C allomorphs with the response to methotrexate (MTX) treatment.

Results: We observed that patients possessing the full-length KIR2DS4 (KIR2DS4f) gene had a lower chance of responding in comparison to KIR2DS4f-negative cases. This phenomenon was observed both in erosive disease (ED) and rheumatoid factor (RF) positive and in ED- and RF-negative patients. Interestingly, the observed effect of the KIR2DS4f gene was strongest in individuals possessing medium values $(20-33 \mathrm{~mm} / \mathrm{h})$ of the erythrocyte sedimentation rate (ESR). Patients with high ESR values had low probability and, in contrast, patients with low ESR had a high probability of MTX response, and the presence of KIR2DS4f did not affect their outcome. Additionally, we show that the KIR2DS4f effect did not depend on the presence of either C1 or C2 allomorphs.

Conclusion: Our results suggest that the response of RA patients with medium ESR values to MTX treatment may be dependent on the full-length KIR2DS4 gene.

Keywords: Rheumatoid arthritis, Treatment response, Methotrexate, KIR, KIR ligand

\section{Background}

Rheumatoid arthritis (RA) is a chronic, relatively prevalent (about $1 \%$ of individuals in Caucasians) inflammatory disorder with a T cell-mediated autoimmune component [1]. Natural killer (NK) cells were also reported to contribute to RA [2]. These cells may act both directly, killing target cells, and indirectly, as either inducer or regulatory cells

\footnotetext{
* Correspondence: e.majorczyk@po.opole.pl; pkusnier@iitd.pan.wroc.pl 'Laboratory of Immunogenetics and Tissue Immunology, Ludwik Hirszfeld Institute of Immunology and Experimental Therapy, Polish Academy of Sciences, Weigla 12, 53-114 Wrocław, Poland

${ }^{2}$ Biochemistry and Physiology, Institute of Physiotherapy, Faculty of Physical Education and Physiotherapy, Opole University of Technology, Proszkowska 76, 45-758 Opole, Poland

Full list of author information is available at the end of the article
}

influencing innate and adaptive immunity (a "two-edged weapon") [3].

The most polymorphic receptors of NK cells are encoded by killer cell immunoglobulin-like receptor (KIR) genes distributed differently in unrelated individuals. Since these receptors, depending on their structure, are either inhibitory or activating, their repertoire in a genotype affects activity of NK cells (and T cell subpopulations which also express KIRs, including T lymphocyte CD4 + CD28$\mathrm{KIR}+$ ) and, in consequence, susceptibility to different diseases including autoimmune disorders such as RA [4-6]. KIR haplotypes (i.e., sets of KIR genes on one chromosome) have been divided into group A, containing mostly inhibitory genes, and group $\mathrm{B}$, containing several activating genes 
in addition to inhibitory ones. Moreover, the whole KIR region was divided into centromeric (A or $\mathrm{B}$ ) and telomeric (A or B) halves, depending on the KIR gene content [7].

Ligands of KIRs, in most cases where known, are human leukocyte antigen (HLA) class I molecules which are extremely polymorphic. KIR and $H L A$ genes are located on different chromosomes (number 19 and 6, respectively); therefore they are independently inherited and an individual may have KIRs with no ligands and vice versa. This affects the maturation of NK cells and the susceptibility of an individual to disease [8,9]. The most important ligands of KIRs are HLA-C molecules, which all fall into two groups: $\mathrm{C} 1$, with an asparagine residue in position 80 , and $C 2$, with a lysine residue in this position. KIR2DL1 and KIR2DS1 are receptors for the C2 epitope, whereas KIR2DL2 and KIR2DL3 bind $\mathrm{C} 1$ and also some $\mathrm{C} 2$ molecules. KIR2DS4 recognizes HLA-A*11 molecules as well as some $\mathrm{C} 1$ and $\mathrm{C} 2$. KIR2DL4 binds the "non-classical" class I molecule HLA-G. KIR3DL1 and possibly KIR3DS1 bind HLA-B with Bw4 epitope and those HLA-A alleles that possess the Bw4 motif. KIR3DL2 binds HLA-A $03,{ }^{*} 11$, and microbial CpG DNA [10]. In addition, both KIR3DL1 and KIR3DL2 bind HLA-B*27 homodimers [11,12].

As KIR and KIR ligand genotypes affect the immune response, and seem to influence the response to RA treatment using anti-TNF- $\alpha$ agents [13], we wondered whether these genotypes might also influence the outcome of MTX therapy of RA. MTX as a foliate antagonist is used in therapy of malignant disorders, but also suppresses the immune response in patients and in low doses was introduced for the treatment of RA because of its presumed antiproliferative, immunosuppressive and anti-inflammatory properties [14]. However, MTX is not sufficient in all RA patients, and approximately $50-60 \%$ of RA patients could be classified as MTX responders [15-18]. It seems that the effectiveness of MTX treatment corresponds to the individual genetic background, particularly in genes encoding key molecules of methotrexate metabolism and toxicity $[19,20]$. However, clinically reliable markers of methotrexate efficiency are still sought.

\section{Methods}

\section{Study subjects}

Three hundred and twelve patients (253 females, 59 males; mean age, $58.0 \pm 12.7$ years, range 23-90; disease duration, $10.0 \pm 8.8$ years, range 1-50; age at onset $48.0 \pm$ 13.1, range 10-80) were diagnosed with RA according to the criteria of the American College of Rheumatology (Table 1). Patients were recruited from the outpatient and inpatient population of the Department of Rheumatology, County Hospital in Szczecin, Poland. All subjects were Caucasian, from the Pomeranian region of Poland. The subjects enrolled in the study underwent routine biochemical blood analysis, and when required, assays for anti-cardiolipin antibodies, anti-nuclear antibodies, and immunological complexes. X-rays of the chest, hands, and feet were obtained in all patients and, when required, radiographs of other joints. These were interpreted by two expert radiologists. The evaluation of the subjects included physical examination, with particular focus on the pattern of joint involvement and the occurrence of extra-articular features (such as vasculitis, anemia, sicca syndrome, amyloidosis, organ involvement) and laboratory features, such as rheumatoid factor (RF) and anti-cyclic citrullinated peptide antibodies (anti-CCP) screened for using appropriate ELISA kits. Amyloidosis was diagnosed by histomorphology (skin and bowel or duodenum biopsy), vasculitis by histomorphology (skin biopsy) and angiogram.

All patients included in this analysis had a standard methotrexate treatment with a regimen of oral $7.5 \mathrm{mg}$ weekly, and with the dosage increasing to $20 \mathrm{mg}$ weekly after 4 weeks, in combination with folic acid $(1 \mathrm{mg}$ daily). No patients received any other disease-modifying antirheumatic drug (DMARD), and no researchers' involvement in the patient care was practiced. A good MTX response was noted for patients who were receiving MTX and had a disease activity score based on 28 joint counts (DAS28) of $\leq 2.5$ at 6 months. Poor responders were defined as patients who were also receiving MTX but had a DAS28 of $>2.5[21,22]$.

The study was approved by the Committee of Ethical Affairs of the Pomeranian Medical University in Szczecin and written informed consent was obtained from all subjects.

\section{DNA isolation, KIR and KIR ligand typing}

These procedures were performed as described previously $[23,24]$.

\section{Statistical analysis}

To investigate relationship between genetic, clinical and anthropological variables and probability of a

Table 1 Characteristics of patients with rheumatoid arthritis

\begin{tabular}{lccc}
\hline Groups & $\begin{array}{c}\text { Number of cases } \\
\text { (females/males) }\end{array}$ & $\begin{array}{c}\text { Age } \\
\text { (mean } \pm \text { SD, range) }\end{array}$ & $\begin{array}{c}\text { Disease duration } \\
\text { (mean } \pm \text { SD, range) }\end{array}$ \\
\hline All cases & $312(253 / 59)$ & $58.0 \pm 12.7,23-90$ & $10.0 \pm 8.8,1-50$ \\
Good responders & $179(143 / 36)$ & $59.4 \pm 12.4,23-84$ & $9.0 . \pm 7.3,1-37$ \\
Poor responders & $133(110 / 23)$ & $56.1 \pm 12.9,24-90$ & $11.3 \pm 10.0,1-50$ \\
\hline
\end{tabular}


Table 2 KIR gene distribution and its effect on MTX response

\begin{tabular}{|c|c|c|c|c|c|c|c|c|c|c|c|}
\hline \multirow{2}{*}{$\begin{array}{c}\text { MTX } \\
\text { response }\end{array}$} & \multicolumn{11}{|c|}{ KIR genes } \\
\hline & $2 D S 2$ & $2 D L 3$ & $2 D L 2$ & $2 D S 3$ & $2 D L 1$ & $3 D L 1$ & $3 D S 1$ & $2 D S 5$ & 2DS1 & $2 D S 4 f^{*}$ & 2DS4d \\
\hline \multicolumn{12}{|c|}{ Good responders $(N=179)$} \\
\hline Presence $(\mathrm{N})$ & 107 & 155 & 103 & 68 & 178 & 171 & 59 & 52 & 71 & 55 & 156 \\
\hline Absence $(\mathrm{N})$ & 7 & 24 & 76 & 111 & 21 & 8 & 120 & 127 & 108 & 124 & 23 \\
\hline Frequency [\%] & 59.78 & 86.59 & 57.54 & 37.99 & 99.44 & 95.53 & 32.96 & 29.05 & 39.66 & 30.73 & 87.15 \\
\hline \multicolumn{12}{|c|}{ Poor responders $(\mathrm{N}=133)$} \\
\hline Presence $(\mathrm{N})$ & 75 & 121 & 71 & 33 & 129 & 121 & 46 & 41 & 55 & 50 & 110 \\
\hline Absence $(\mathrm{N})$ & 5 & 12 & 62 & 100 & 84 & 12 & 87 & 92 & 78 & 83 & 23 \\
\hline Frequency [\%] & 56.39 & 90.98 & 53.38 & 24.81 & 96.99 & 90.98 & 34.59 & 30.83 & 41.35 & 37.59 & 82.71 \\
\hline
\end{tabular}

*Good responders vs poor responders: $\mathrm{p}=0.0334 ; \mathrm{OR}=0.43,95 \% \mathrm{Cl}=0.215-0.987$.

good response to MTX treatment, a generalized linear model with binomial errors was used. The Akaike information criterion was used as a measure of fit of models.

A bootstrap approach was employed to estimate model coefficients and 95\% confidence intervals. Odds ratio (OR) was computed as a measure of effect size. Arithmetic mean and standard deviation were calculated for continuous variables. Haplotype frequencies for KIR repertoire were estimated with maximum likelihood function [25]. The likelihood ratio statistic, LRS, was used to test the differences in haplotype frequencies between good responders and poor responders. $L R S_{d f=21}=2\left(L L_{\text {good }}+\right.$ $\left.L L_{\text {poor }}-L L_{\text {combined }}\right)$ and LRS is approximately a $\chi_{d f=21}^{2}$. Results were regarded as statistically significant at $\mathrm{p}<0.05$.

\section{Results}

A clinical response to MTX therapy was obtained for $57.3 \%$ of RA patients. When the frequencies of the KIR genes were compared between good responders and poor responders of RA patient groups, we observed an effect of only one KIR gene, full-length KIR2DS4 (KIR2DS4f), on the response to MTX therapy. Namely, patients possessing this gene had a lower chance of responding $(\mathrm{p}=0.0334, \mathrm{OR}=0.4344,95 \% \mathrm{CI}=0.215$, 0.987; Table 2). Additionally, patients with erosive disease (ED) and rheumatoid factor (RF) were less likely to respond to MTX, and those positive for KIR2DS4f had an even lower chance than those who were negative for KIR2DS4f but positive for both ED and RF $(36.2 \%$ and $43.6 \%$ of good responders, respectively; Table 3). Similarly, RA patients negative for ED and RF also had a lower chance of responding to MTX therapy if they possessed KIR2DS4f (75\% responding in comparison to $88 \%$ within KIR2DS4f-negative patients; Table 3). On the other hand, the presence of KIR2DS4 $f$ did not affect the formation of RF $(\mathrm{p}=0.89)$, ED $(\mathrm{p}=0.78)$, or other clinical parameters (data not shown).
The KIR2DS4f gene is located in the telomeric half of the KIR locus [7]. However, we did not observe any differences between good and poor MTX responders in the estimated haplotype frequencies for the telomeric KIR repertoire $(\mathrm{p}=0.29$; Figure 1$)$ despite the association of the KIR2DS4f gene with a poor response to MTX described above. Also, there were no differences in frequencies of centromeric $(\mathrm{p}=0.71)$ or whole KIR locus $(\mathrm{p}=0.96)$ genotypes between good and poor responders.

The effect of the KIR2DS4f gene on the probability of a response to MTX in RF- and ED-positive patients was strongest in individuals with medium values of the erythrocyte sedimentation rate (ESR), that is, $\log (\mathrm{ESR})$ about $3.0-3.5$, i.e. $20-33 \mathrm{~mm} / \mathrm{h}$ (Figure 2). Patients with high ESR values had a low probability of responding, and the presence or absence of KIR2DS4 $f$ did not affect their outcome, particularly in individuals with low age at onset. Patients with low ESR had a high probability of responding, which was not affected by the presence of KIR2DS4f, particularly in people with high age at onset (Figure 2). The KIR2DS4f effect did not depend on the presence of $\mathrm{C} 1(\mathrm{p}=0.209)$ or $\mathrm{C} 2(\mathrm{p}=0.484)$. Surprisingly, the age at diagnosis had a negligible influence on the KIR2DS4f effect.

\begin{tabular}{|c|c|c|c|}
\hline \multicolumn{2}{|c|}{ MTX responsiveness } & \multicolumn{2}{|c|}{ Frequency (good responders/all) } \\
\hline ED & RF & 2DS4f presence & 2DS4f absence \\
\hline+ & + & $36.2(21 / 58)$ & $43.6(48 / 110)$ \\
\hline+ & - & $70.0(14 / 20)$ & $76.7(33 / 43)$ \\
\hline- & + & $72.7(8 / 11)$ & $72.4(21 / 29)$ \\
\hline- & - & $75.0(12 / 16)$ & $88.0(22 / 25)$ \\
\hline
\end{tabular}

+, clinical factor detected; -, clinical factor absent. 


\begin{tabular}{|c|c|c|c|c|c|c|c|c|c|}
\hline \multicolumn{9}{|c|}{ Telomeric KIR genes } & \\
\hline \multirow{2}{*}{$\begin{array}{r}\text { No. } \\
1\end{array}$} & 3DL1 & 3DS1 & 2DS5 & 2DS1 & $2 \mathrm{DS} 4 \mathrm{f}$ & $2 \mathrm{DS} 4 \mathrm{~d}$ & Good-responders & Poor-responders & \\
\hline & & & & & & & 58.68 & 52.62 & \\
\hline 2 & & & & & & & 14.63 & 18.44 & \\
\hline \multirow[t]{2}{*}{3} & & & & & & & 9.53 & 13.4 & \\
\hline & & & & & & & 6.38 & 5.21 & \\
\hline 4 & & & & & & & 2.02 & 3.01 & \\
\hline 6 & & & & & & & 1.52 & 0.82 & \\
\hline 7 & & & & & & & 1.21 & 0.78 & \\
\hline \multirow[t]{2}{*}{8} & & & & & & & 0.94 & $<0.02$ & \\
\hline & & & & & & & 0.92 & $<0.02$ & \\
\hline 10 & & & & & & & 0.86 & 1.1 & \\
\hline 11 & & & & & & & 0.82 & $<0.02$ & \\
\hline 12 & & & & & & & 0.8 & $<0.02$ & \\
\hline 13 & & & & & & & 0.61 & 1.15 & \\
\hline 14 & & & & & & & 0.4 & 1.66 & \\
\hline 15 & & & & & & & 0.3 & $<0.02$ & \\
\hline 16 & & & & & & & 0.15 & 0.39 & \\
\hline 17 & & & & & & & 0.11 & 0.03 & \\
\hline 18 & & & & & & & 0.09 & 0.35 & \\
\hline 19 & & & & & & & 0.03 & $<0.02$ & \\
\hline 20 & & & & & & & $<0.02$ & 0.71 & \\
\hline \multirow[t]{2}{*}{21} & & & & & & & $<0.02$ & 0.33 & \\
\hline & \multicolumn{7}{|r|}{$\Sigma 100 \%$} & $\Sigma 100 \%$ & \\
\hline \multicolumn{10}{|c|}{$\begin{array}{l}\text { Figure } 1 \text { Telomeric KIR haplotype profiles in MTX good responder and poor responder RA patient groups. Grey box: gene presence; } \\
\text { white box: gene absence. Estimation of KIR gene frequency based on haplotype distributions shown for KIR3DL1 - 81.5\% and 78.7\%, for KIR3DS1 } \\
18.6 \% \text { and } 21.5 \% \text {, for KIR2DS5 } 15.9 \% \text { and } 18.1 \% \text {, for KIR2DS1 } 22.4 \% \text { and } 26.0 \% \text {, for KIR2DS4f } 16.4 \% \text { and } 20.3 \% \text {, for KIR2DS4d } 63.3 \% \text { and } 56.3 \% \text {, in } \\
\text { good responder and poor responder groups, respectively. }\end{array}$} \\
\hline
\end{tabular}

\section{Discussion}

This report confirms that almost one third of patients affected by rheumatoid arthritis do not respond to lowdose MTX treatment [15-18]. This phenomenon causes that the discovery of (bio)markers of response to the drug is still required for clinical practice. Here, we found a negative association of the KIR2DS4f gene with the response of RA patients to MTX treatment. This effect was visible not only in RF-positive, ED-positive patients who already had a lower chance of responding than negative ones, but also in RF- and ED-negative individuals who otherwise were better responders. Therefore, it is likely that the KIR2DS4f gene is expressed on effectors or positive regulators or inducers of autoimmune response, relatively resistant to the MTX effect. In this context, the CD4+CD28- subpopulation of $\mathrm{T}$ lymphocytes should be discussed. This $\mathrm{T}$ cell subset is rare in healthy individuals (about 1\% of peripheral lymphocytes), but its expansion was observed in patients affected by, e.g., coronary artery disease [26], polycystic ovary syndrome [27], multiple sclerosis [28] and rheumatoid arthritis [4,29,30]. In contrast to those isolated from healthy volunteers [31], CD4+CD28- $\mathrm{T}$ cells from rheumatoid arthritis patients may exhibit autoreactive properties [4]. Instead of the CD28 molecule, these $T$ cells frequently express activating KIR receptors, as was shown by Yen et al. [32] particularly for KIR2DS2 in RA vasculitis. Interestingly, it was suggested that the KIR2DS4 gene may also be expressed on CD4+CD28- T lymphocytes [33], and could transmit an activating signal to effector cells. Therefore, KIR2DS4f gene-positive patients might have a potential to produce CD4+CD28-KIR2DS4+ T cells contributing to more severe forms of RA, which would be more resistant to therapy, including MTX treatment. 


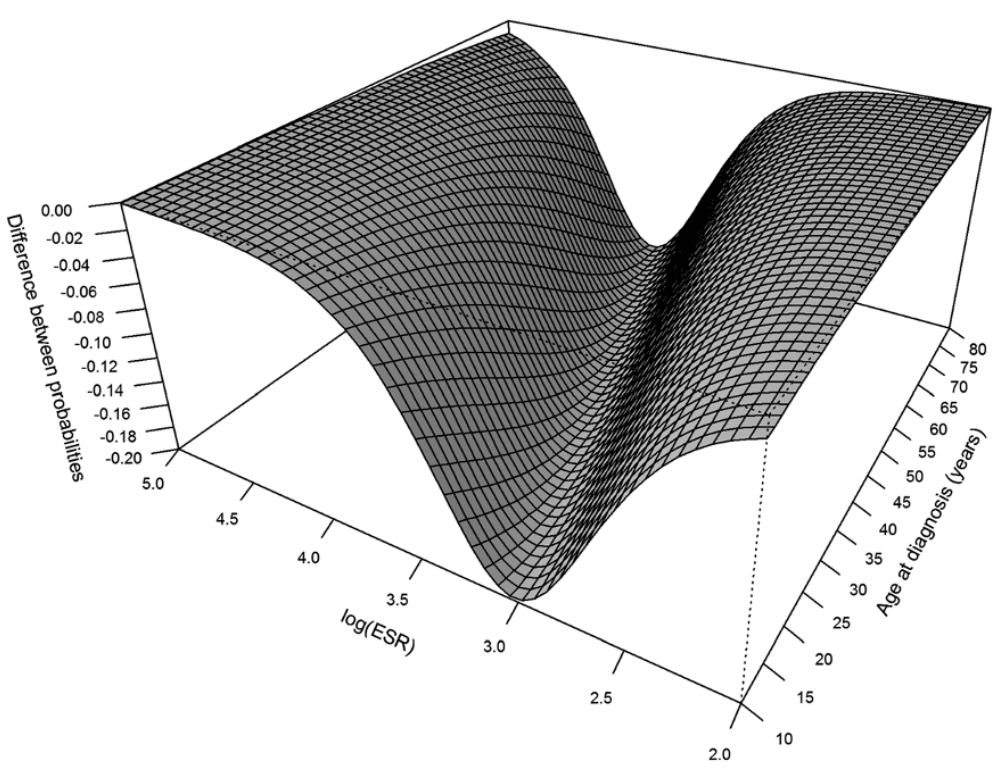

Figure 2 Probability difference in MTX response between KIR2DS4f-positive and KIR2DS4f-negative patients with similar RA baseline.

The gene mentioned above encodes the KIR2DS4f polyspecific receptor recognizing both HLA-A*11 and some HLA-C allotypes bearing C1 or C2 epitopes [10]. In Caucasians, including Poles, its gene is present in roughly one third of KIR2DS4-positive individuals, the other two thirds bearing its defective alleles, KIR2DS4d (see www.allelefrequencies.net database) [34], potentially encoding a soluble molecule which does not exhibit any activating properties [35]. However, in Far East Orientals, Japanese and Chinese, the proportions between KIR2DS4f and KIR2DS4d are reversed [33]. It would be interesting, then, to perform a similar analysis of RA patients' response to MTX therapy in those populations, especially as the KIR2DS4 gene seems to impact on RA susceptibility in Taiwanese patients [36].

Some studies suggest that ESR level, mentioned as a biomarker for chronic systemic inflammation as well as a parameter of disease activity, correlated with responsiveness to MTX (reviewed by Romao et al.) [37]. In the present study, we see that the effect of KIR2DS4f is strongest in individuals with medium susceptibility to the therapeutic effect of MTX characterized by an intermediate level of ESR. Patients with high ESR are resistant to therapy, and lack of the KIR2DS4f gene cannot help them; those with low ESR respond so well that even the presence of the KIR2DS4f gene does not cause any harm.

\section{Conclusion}

This study shows that the presence of the full-length KIR2DS4 gene reduces the probability that patients affected by rheumatoid arthritis will respond to methotrexate therapy. This phenomenon was strongest in individuals with a medium level $(20-33 \mathrm{~mm} / \mathrm{h})$ of the erythrocyte sedimentation rate. The patient cohort with lower values of ERS responded better to MTX, while patients with a higher ESR level responded worse to therapy, and the presence of KIR2DS4f did not affect their outcome. Therefore, our findings, if confirmed using an independent and larger group of patients, might suggest that KIR typing could help to predict the response to MTX therapy, especially for patients with moderate rheumatoid arthritis.

\section{Abbreviations}

CCP: Cyclic citrullinated peptide; ED: Erosive disease; ESR: Erythrocyte sedimentation rate; HLA: Human leukocyte antigen; KIR: Killer cell immunoglobulin-like receptor; LRS: Likelihood ratio statistic; MTX: Methotrexate; NK: Natural killer; OR: Odds ratio; RA: Rheumatoid arthritis; RF: Rheumatoid factor.

\section{Competing interests}

The authors declare that they have no competing interests.

\section{Authors' contributions}

EM conducted the study and participated in the study design, data analysis and interpretation and drafting of the manuscript; AP participated in the data collection and drafting of the manuscript; DG contributed to the samples genotyping; PK participated in the study design, data analysis and interpretation as well as in the drafting of the manuscript. All authors read and approved the final manuscript.

\section{Acknowledgements}

This work was supported by grant no. N N402 641140 from the Polish National Science Centre and by the Ludwik Hirszfeld Institute of Immunology and Experimental Therapy grant no. 14/2014.

\section{Author details}

${ }^{1}$ Laboratory of Immunogenetics and Tissue Immunology, Ludwik Hirszfeld Institute of Immunology and Experimental Therapy, Polish Academy of Sciences, Weigla 12, 53-114 Wrocław, Poland. ${ }^{2}$ Biochemistry and Physiology, Institute of Physiotherapy, Faculty of Physical Education and Physiotherapy, Opole University of Technology, Proszkowska 76, 45-758 Opole, Poland. ${ }^{3}$ Pharmacokinetics and Therapeutic Drug Monitoring, Pomeranian University of Medicine, Powstańców Wlkp. 72, 70-111 Szczecin, Poland. 
Received: 26 August 2013 Accepted: 30 June 2014

Published: 28 July 2014

\section{References}

1. Jacob N, Jacob CO: Genetics of rheumatoid arthritis: an impressionist perspective. Rheum Dis Clin North Am 2012, 38:243-257.

2. Falgarone $G$, Jaen $O$, Boissier MC: Role for innate immunity in rheumatoid arthritis. Joint Bone Spine 2005, 72:17-25.

3. Tian Z, Gershwin ME, Zhang C: Regulatory NK cells in autoimmune response. J Autoimm 2012, 39:206-215.

4. Namekawa T, Snyder MR, Yen J-H, Goehring BE, Leibson PJ, Weyand CM, Goronzy JJ: Killer cell activating receptors function as costimulatory molecules on CD4 + CD28null T cells clonally expanded in rheumatoid arthritis. J Immunol 2000, 165:1138-1145.

5. Parham P: MHC class I molecules and KIRs in human history, health and survival. Nat Rev Immunol 2005, 5:201-214.

6. Rajalingam R: Human diversity of killer cell immunoglobulin-like receptors and disease. Korean J Hematol 2011, 46:216-228.

7. Cooley S, Wesdorf DJ, Guethlein LA, Klein JP, Wang T, Le CT, Marsh SG Geraghty D, Spellman S, Haagenson MD, Ladner M, Trachtenberg E, Parham $P$, Miller JS: Donor selection for natural killer cell receptor genes leads to superior survival after unrelated transplantation for acute myelogenous leukemia. Blood 2010, 116:2411-2419.

8. Yokoyama WM: Inhibitory receptors signal activation. Immunity 2008 , 29:515-517.

9. Raulet $\mathrm{DH}$, Vance RE, McMahon CW: Regulation of the natural killer cell receptor repertoire. Annu Rev Immunol 2001, 19:291-330.

10. Kuśnierczyk P: Killer cell immunoglobulin-like receptor gene associations with autoimmune and allergic diseases, recurrent spontaneous abortion, and neoplasms. Front Immunol 2013, doi:10.3389/fimmu.2013.00008.

11. Cauli A, Shaw J, Giles J, Hatano H, Rysnik O, Payeli S, McHugh K, Dessole G, Porru G, Desogus E, Fiedler S, Hölper S, Carette A, Blanco-Gelaz MA, Vacca A, Piga M, Ibba V, Garau P, La Nasa G, López-Larrea C, Mathieu A, Renner C, Bowness $P$, Kollnberger S: The arthritis-associated HLA-B*27:05 allele forms more cell surface B27 dimer and free heavy chain ligands for KIR3DL2 than HLAB*27:09. Rheumatology 2013, 52:1952-1962.

12. Kuśnierczyk $P$, Majorczyk E: Pas de quatre: an interaction of HLA-B*2705 and KIR3DL2 homodimers in spondyloarthropathies. Rheumatology 2013, 52:1931-1932.

13. McGeough CM, Berrar D, Wright G, Mathews C, Gilmore P, Cunningham RT, Bjourson AJ: Killer immunoglobulin-like receptor and human leukocyte antigen- $C$ genotypes in rheumatoid arthritis primary responders and non-responders to anti-TNF-a therapy. Rheumatol Int 2012, 32:1647-1653.

14. Cronstein BN: Going with the flow: methotrexate, adenosine, and blood flow. Ann Rheum Dis 2006, 65:421-422.

15. Capone D, Spanò A, Gentile A, Ferrara G, Itto E, Palmiero G, Basile V, Oriente $P$ : Are there differences in methotrexate kinetics between responding and nonresponding patients with rheumatoid arthritis? BioDrugs 2000, 13:373-379

16. Marchesoni A, Battafarano N, Arreghini M, Panni B, Gallazzi M, Tosi S: Radiographic progression in early rheumatoid arthritis: a 12-month randomized controlled study comparing the combination of cyclosporin and methotrexate with methotrexate alone. Rheumatology (Oxford) 2003, 42:1545-1549

17. Dervieux T, Furst D, Lein DO, Capps R, Smith K, Walsh M, Kremer J: Polyglutamation of methotrexate with common polymorphisms in reduced folate carrier, aminoimidazole carboxamide ribonucleotide transformylase, and thymidylate synthase are associated with methotrexate effects in rheumatoid arthritis. Arthritis Rheum 2004, 50:2766-2774

18. Maillefert JF, Puéchal X, Falgarone G, Lizard G, Ornetti P, Solau E, Legré V, Lioté F, Sibilia J, Morel J, Maynadié M, Réseau Rhumato Study Group: Prediction of response to disease modifying antirheumatic drugs in rheumatoid arthritis. Joint Bone Spine 2010, 77:558-563.

19. Aslibekyan S, Brown EE, Reynolds RJ, Redden DT, Morgan S, Baggott JE, Sha J, Moreland LW, O'Dell JR, Curtis JR, Mikuls TR, Bridges SL Jr, Arnett DK: Genetic variants associated with methotrexate efficacy and toxicity in early rheumatoid arthritis: results from the treatment of early aggressive rheumatoid arthritis trial. Pharmacogenomics J 2014, 14:48-53.

20. Owen SA, Hider SL, Martin P, Bruce IN, Barton A, Thomson W: Genetic polymorphisms in key methotrexate pathway genes are associated with response to treatment in rheumatoid arthritis patients. Pharmacogenomics $J$ 2013, 13:227-234.

21. Felson DT, Anderson JJ, Boers M, Bombardier C, Chernoff M, Fried B, Furst D, Goldsmith C, Kieszak S, Lightfoot R, Paulus H, Tugwell P, Weinblatt M, Widmark R, Williams HJ, Wolfe F: The American College of Rheumatology preliminary core set of disease activity measures for rheumatoid arthritis clinical trials. The Committee on Outcome Measures in Rheumatoid Arthritis Clinical Trials. Arthritis Rheum 1993, 3:729-740.

22. Fuchs HA, Brooks RH, Callahan LF, Pincus T: A simplified twenty-eight-joint quantitative articular index in rheumatoid arthritis. Arthritis Rheum 1989, 32:531-537.

23. Majorczyk E, Pawlik A, Łuszczek W, Nowak I, Wiśniewski A, Jasek M, Kuśnierczyk P: Associations of killer cell immunoglobulin-like receptor genes with complications of rheumatoid arthritis. Genes Immun 2007, 8:678-683.

24. Frohn C, Schlenke P, Ebel B, Dannenberg C, Bein G, Kitchner H: DNA typing for natural killer cell inhibiting HLA-Cw groups NK1 and NK2 by PCR-SSP. J Immunol Meth 1998, 218:155-160.

25. Excoffier $L$, Slatkin M: Maximum-likelihood estimation of molecular haplotype frequencies in a diploid population. Mol Biol Evol 1995, 12:921-927.

26. Téo FH, de Oliveira RT, Mamoni RL, Ferreira MC, Nadruz W Jr, Coelho OR, Fernandes Jde L, Blotta MH: Characterization of CD4 + CD28null T cells in patients with coronary artery disease and individuals with risk factors for atherosclerosis. Cell Immunol 2013, 281:11-19

27. Niccoli G, Apa R, Lanzone A, Liuzzo G, Spaziani C, Sagnella F, Cosentino N, Moro F, Martinez D, Morciano A, Bacà M, Pazzano V, Gangale MF, Tropea A Crea F: CD4 + CD28 null T lymphocytes are expanded in young women with polycystic ovary syndrome. Fertil Steril 2011, 95:2651-2654.

28. Pinto-Medel MJ, García-León JA, Oliver-Martos B, López-Gómez C, Luque G, Arnáiz-Urrutia C, Orpez T, Marín-Bañasco C, Fernández O, Leyva L: The CD4+ T-cell subset lacking expression of the CD28 costimulatory molecule is expanded and shows a higher activation state in multiple sclerosis. J Neuroimmunol 2012, 243:1-11

29. Pawlik A, Ostanek L, Brzosko I, Brzosko M, Masiuk M, Machalinski B, Gawrońska-Szklarz B: The expansion of CD4 + CD28- T cells in patients with rheumatoid arthritis. Arthritis Res Ther 2003, 5:R210-R213.

30. Smoleńska Ż, Pawłowska J, Daca A, Soroczyńska-Cybula M, Witkowski J, Bry EM: Disease activity in patients with long-lasting rheumatoid arthritis is associated with changes in peripheral blood lymphocyte subpopulations. Pol Arch Med Wewn 2012, 122:591-598.

31. van Bergen J, Thompson A, van der Slik A, Ottenhoff THM, Gussekloo J, Koning F: Phenotypic and functional characterization of CD4 T cells expressing killer Ig-like receptors. J Immunol 2004, 173:6719-6726.

32. Yen JH, Moore BE, Nakajima T, Scholl D, Schaid DJ, Weyand CM, Goronzy JJ: Major histocompatibility complex class I-recognizing receptors are disease risk genes in rheumatoid arthritis. J Exp Med 2001, 193:1159-1167.

33. Nowak I, Magott-Procelewska M, Kowal A, Miazga M, Wagner M, NiepiekłoMiniewska W, Kamińska M, Wiśniewski A, Majorczyk E, Klinger M, Łuszczek W, Pawlik A, Płoski R, Barcz E, Senitzer D, Kuśnierczyk P: Killer immunoglobulin-like receptor (KIR) and HLA genotypes affect the outcome of allogeneic kidney transplantation. PLOS One 2012, 7:e44718.

34. Gonzalez-Galarza FF, Christmas S, Middleton D, Jones AR: Allele frequency net: a database and online repository for immune gene frequencies in worldwide populations. Nucleic Acids Res 2011, 39:D913-D919.

35. Middleton D, Gonzalez A, Gilmore PM: Studies on the expression of the deleted KIR2DS4*003 gene product and distribution of KIR2DS4 deleted and nondeleted versions in different populations. Hum Immunol 2007, 68:128-134

36. Yen JH, Lin CH, Tsai WC, Wu CC, Ou TT, Hu CJ, Liu HW: Killer cell immunoglobulin-like receptor gene's repertoire in rheumatoid arthritis. Scand J Rheumatol 2006, 35:124-127.

37. Romão VC, Canhão H, Fonseca JE: Old drugs, old problems: where do we stand in prediction of rheumatoid arthritis responsiveness to methotrexate and other synthetic DMARDs? BMC Medicine 2013, 11:17

doi:10.1186/1471-2474-15-256

Cite this article as: Majorczyk et al:: Presence of the full-length KIR2DS4 gene reduces the chance of rheumatoid arthritis patients to respond to methotrexate treatment. BMC Musculoskeletal Disorders 2014 15:256. 